IZA DP No. 8511

Public Employment Policies and Regional Unemployment Differences

Vincenzo Caponi 


\title{
Public Employment Policies and Regional Unemployment Differences
}

\author{
Vincenzo Caponi \\ CREST-ENSAI, Ryerson University, \\ IfW and IZA
}

\section{Discussion Paper No. 8511 September 2014}

\author{
IZA \\ P.O. Box 7240 \\ 53072 Bonn \\ Germany \\ Phone: +49-228-3894-0 \\ Fax: +49-228-3894-180 \\ E-mail: iza@iza.org
}

Any opinions expressed here are those of the author(s) and not those of IZA. Research published in this series may include views on policy, but the institute itself takes no institutional policy positions. The IZA research network is committed to the IZA Guiding Principles of Research Integrity.

The Institute for the Study of Labor (IZA) in Bonn is a local and virtual international research center and a place of communication between science, politics and business. IZA is an independent nonprofit organization supported by Deutsche Post Foundation. The center is associated with the University of Bonn and offers a stimulating research environment through its international network, workshops and conferences, data service, project support, research visits and doctoral program. IZA engages in (i) original and internationally competitive research in all fields of labor economics, (ii) development of policy concepts, and (iii) dissemination of research results and concepts to the interested public.

IZA Discussion Papers often represent preliminary work and are circulated to encourage discussion. Citation of such a paper should account for its provisional character. A revised version may be available directly from the author. 
IZA Discussion Paper No. 8511

September 2014

\section{ABSTRACT}

\section{Public Employment Policies and Regional Unemployment Differences}

This paper contributes to the existing literature on public employment showing that the wage setting policy of the public sector can be an important determinant of private employment and unemployment. I look at the case of geographically homogeneous wages across regions with different private sector productivity, and show that public employment generates a crowding out effect against private employment. This effect is larger the larger is the public sector share of total employment. I present a two region two sector model based on Pissarides (2000) heterogeneous search and matching model where vacancies are posted by the private and the public sector as in Quadrini and Trigari (2007) and Gomes (2014). I calibrate the model to the Italian labor market and show that the uniform wage setting policy adopted by the central government, in the presence of productivity unbalance across regions, is responsible for up to $40 \%$ of the unemployment gap between the North and South. Policy experiments suggest that reducing the size of public employment reduces unemployment in lower productive regions while allowing for regional wage setting in the public sector almost eliminates the unemployment differential.

JEL Classification: E24, J60

Keywords: Italy, European unemployment, regional unemployment, public employment

Corresponding author:

Vincenzo Caponi

Ensai - Campus de Ker Lann

rue Blaise Pascal - BP 37203

35172 Bruz cedex

France

E-mail: vcaponi@ryerson.ca 


\section{Introduction}

A few studies look the macroeconomic effects of public employment on private, focusing especially on the size of public employment. Among these studies Algan, Cahuc and Zylberberg (2002), analyzing a panel of OECD countries between 1960 and 2000, find evidence that for any additional public employee one and a half jobs are lost in the private sector. Because of a decrease of labor participation, however, in their analysis this translates in only one third of additional workers in the unemployment pool. That is, they do find evidence that a crowding out effect exists and it is higher than $100 \%$. Similar findings are provided by Malley and Moutos (1996) for Sweden and Malley and Moutos (2001) for Germany, Japan and the US. Mixed empirical evidence is instead reported in the analysis of Lamo, Prez and Snchez-Fuentes (2013). They find positive correlations as well as negative between public and private employment analyzing the variations in the size of employment at business cycle frequencies. They conclude that the different sign is mainly due to the relative rigidity in the labor market as well as the lack of competition in the goods market. The theoretical literature on this relationship is more scarce than the empirical one and mainly focused on static partial equilibrium models that illustrate the empirical findings. A general equilibrium model is instead provided in Ardagna (2007). In her model Ardagna assumes that wages are set by unions and that an increase in public employment increases the unions' bargaining power. This leads to higher private wages and lower employment. Pappa (2009), in a neokeynesian framework with sticky wages, also finds that increases in public employment lead to lower private employment. Quadrini and Trigari (2007) also use a general equilibrium business cycle model in which they focus on explaining the cyclical correlation between public and private employment in the US. The motivation of this paper is to explain the large unemployment gap between the North and the South of Italy, a gap that persists since after the early 1970s. To this extent, I look at the possibly distortive effect that the public sector has on the Italian labor market, by assuring to all its employees across Italy an homogenous wage even though local productivity diverges greatly from one region to another. Because the wage paid by the public sector needs to be attractive in high productive regions, the same wage results relatively large in the low productive ones. In a model where unemployed workers can find jobs in the private or public sector, 
a high wage paid by the public increase the outside option of accepting a private sector wage. As in Ardagna (2007), but without unions, this leads to higher bargained wages and leads to higher unemployment. By calibrating the model I show that the institutional setup in public employment can account for up to $40 \%$ of the unemployment gap between the North and South. Moreover, I conduct two policy experiments that suggest that reducing the size of public employment reduces unemployment in lower productive regions while allowing for regional wage setting in the public sector would almost eliminate the unemployment differential.

The findings in this paper are complementary to those in Gomes (2014). Gomes finds that high wages in the public sector lead unemployed workers to queue for public sector jobs prolonging their unemployment spells. He also finds that the business cycle volatility of unemployment is amplified by public sector wages if they are not counter-cyclical, i.e. if they are less or no reactive to productivity shocks. I find similar results focusing on geographical rather than time productivity differences and homogenous public wages. Moreover, Gomes derives an optimal policy for public wages and shows that if the government follows the optimal policy public employment reduces unemployment during business cycles. I also find that when the government pays heterogeneous wages according to local productivity, an increase in public employment reduces unemployment.

The model I present is a two region economy in which regions are equal in all except for a parameter that indicates the structural productivity of jobs. similarly to Quadrini and Trigari (2007) and Gomes (2014), I extend the Pissarides (2000) heterogeneous search and matching model to include public employment. In order to derive an explicit equation that describes the effect of public sector wages have on the private sector, I assume that workers search in both sectors and offers arrive one at the time from each of the two 1 This increases the value of being unemployed as an option opposed to accepting a private job and, consequently, increases the outside option for that job. Therefore, higher wages paid by the public increase the reservation wage in the private sector and lowers the profitability of matches to employers. I also assume that public jobs are remunerated equally across regions, regardless the different productivity, while wages in private jobs are determined by Nash bargaining between an employer and

\footnotetext{
${ }^{1}$ Gomes (2014) shows that the alternative hypothesis of directed search leads to similar results although the effect of public employment on private wages is determined through market tightness.
} 
her employee. Therefore, because the wage paid by the public needs to be sufficiently high to attract workers in high productivity regions, under an institutional setup that imposes a uniform wage, the wage results as relatively high in low productive regions crowding out private employment.

The model is calibrated to account for several facts about the Italian labor market. Distinguishing between the South and the North of Italy, several facts are worth noting about the different performance of these two regions. First of all, the unemployment rate is and has been very different at least since the 1970s, with the South having an unemployment rate that is three to four times that of the North. Second, the South is significantly less productive than the north. A quick look at GDP per hour worked suggests that one hour worked in the South is worth about $20 \%$ less than in the North, this even if the capital per worker is not significantly different between the two regions. Finally, wages are homogeneous across regions in the public sector, while are about $11 \%$ lower in the South than in the North within the private sector. The next section presents the facts highlighted above about the Italian labor market. Section 3 presents the model, while section 4 shows the calibration exercise and the numerical results. In section 5 the evaluation of two possible policies is introduced. Section 6 concludes.

\section{The facts}

In this section I present statistics on the Italian labor market looking in particular at the role of public employment. I start with evidence that public employment in Italy is uniformly distributed between the North and the South of Italy, when we consider the number of public

jobs as share of the population. This suggests that the Government, which in Italy is highly centralized, does not engage in an active policy of inflating public employment in poorer regions with higher unemployment (i.e. the South). However, when we look at the regional distribution of total employment, the share of public jobs on the total of jobs is significantly higher in the South than in the North. I continue the presentation of the facts on the Italian labor market focusing on men only as they are the object of the calibration exercise. The reason is that in order to present a model as simple as possible that captures the main features of the analysis, I abstract from labor participation decision. While for men the labor participation is uniform 
across regions, for women it's quite heterogeneous and, therefore, it would need to be part of the explained variable in a model that includes them. Indeed, the participation of women to the labor market in the South is much lower compared to the North and this has the implication that, overall, there are more public jobs available to participating men in the South than in the North. Finally, I show evidence that wages are uniformly distributed across regions in the public sector, while in the private Northern workers are paid a premium of about $9 \%$ compared to the wages in the South, conditionally on several personal characteristics and occupations.

\subsection{Public Employment}

This section presents some relevant facts on the Italian labor market that motivate the analysis that follows and are also used for the calibration of the model in the next session. I start with some numbers on the size and distribution of public employment. The data reported in Table 1 are collected from the Italian Ministry of Economy and the National Institute for Statistics (ISTAT). From the Ministry I collected the aggregate number of public employees as reported by December 31st of each year from 2001 to 2010 by Italian region, while from ISTAT I collected the total number of residents as reported on January 1st of each year from 2002 to 2011, also by region. To simplify the exposition of the data I backtrack Istat data by one day making it consistent with the Ministry data and I aggregate further the data to the level of repartitions, that is, North and South of Italy. The first two columns report the numbers of public employees in each year, in the South and the North, columns three and four the total number of residents and columns five and six the percent of public employees on the total population. In this sub-section I take the numbers relative to the whole universe of men and women as I am interested in the overall size of the public sector. However, in the following sub-sections I focus on data on men only for reasons that will be clear later.

There are two important points to take from the table. First of all, the relative size of public employment in the South is similar to the size in the North. This is true especially for the last few years in the decade considered, but the size is not substantially bigger in the South even at the beginning of the decade. In 2001, for example, the South had 5.95 public employees for every 100 residents, while the North had 5.56. That is, the in The South, there were 39 more 
Table 1: Public Employment and Population

\begin{tabular}{c|rrrrrr}
\hline Year & \multicolumn{2}{|c}{ Public Employment } & \multicolumn{2}{c}{ Total Residents } & \multicolumn{2}{c}{ P.E. by Residents } \\
\hline \hline & South & North & South & North & South & North \\
2001 & $1,220,533$ & $2,029,740$ & $20,507,342$ & $36,486,400$ & 5.95 & 5.56 \\
2002 & $1,222,211$ & $2,041,340$ & $20,557,362$ & $36,763,708$ & 5.95 & 5.55 \\
2003 & $1,259,997$ & $2,080,492$ & $20,663,632$ & $37,224,613$ & 6.10 & 5.59 \\
2004 & $1,246,174$ & $2,093,301$ & $20,747,325$ & $37,715,050$ & 6.01 & 5.55 \\
2005 & $1,244,098$ & $2,101,054$ & $20,760,051$ & $37,991,660$ & 5.99 & 5.53 \\
2006 & $1,245,394$ & $2,123,320$ & $20,755,621$ & $38,375,666$ & 6.00 & 5.53 \\
2007 & $1,227,846$ & $2,117,954$ & $20,826,769$ & $38,792,521$ & 5.90 & 5.46 \\
2008 & $1,212,674$ & $2,141,974$ & $20,856,244$ & $39,188,824$ & 5.81 & 5.47 \\
2009 & $1,170,954$ & $2,119,905$ & $20,881,429$ & $39,458,899$ & 5.61 & 5.37 \\
2010 & $1,142,357$ & $2,090,501$ & $20,912,859$ & $39,713,583$ & 5.46 & 5.26 \\
\hline \multicolumn{3}{c}{ Data from Istat and from the Italian Ministry of Economy (Ragioneria } \\
\multicolumn{4}{c}{ Generale dello Stato). }
\end{tabular}

public employees every 10,000 residents. Assuming that the right size of public employment per resident is that in the North of Italy, given a population of about 21 million residents this translates in an excess of public employment of about 81,000 workers, or about $6.7 \%$ of the total public employment in the South. The same calculation for 2010 gives an excess of about $3.5 \%$, a reduction that is well shown by Figure 1. Moreover, the entire excess of public employment can actually be explained by the different demography of the two areas. The sector of public employments that by itself includes most of public workers is education, particularly from kindergarten to high school. In Italy in 2001, 1.13 million employees were in this sector. Looking at the geographical distribution, $2.45 \%$ and $1.73 \%$ are the employees in the school sector per resident in the South and in the North, this would translate into an excess of about 148,000 employees in the South. Yet, this excess is entirely explained by the demographical composition of the South compared to that of the North as employees in the school per child aged between 0 and 19 the South and in the North are very similar (10.1 in the South compared to 10.05 in the North, suggesting an excess of only 2,000 units instead of 148,000) ${ }^{2}$ The main point to take from this analysis is that, while it is a fact, as shown by A., Danninger and Rostagno (2001) that there exists a significant redistribution of income from the North to the

\footnotetext{
${ }^{2}$ Following all the calculations, there seems to be now an excess of public employment in the North rather than in the South, as $148,000-81,000=67,000$. This indeed, can easily be explained by Rome being included in the Northern regions.
} 
South through public employment, this is not the result of an intentional policy that inflates the public sector in the South compared to that in the North. This is an important fact that justifies the model I propose in section 3, where I assume that the government fixes the number of public employees to be hired in each region exogenously, and particularly independently from the level of unemployment. The model predicts the income redistribution between the North and the South, as an equilibrium outcome that results from several forces at play, the main of which is a homogeneous wage paid by the public administration combined with a productivity deficit of the South compared to the North that depresses labor participation and increases unemployment in the South. This translates in a much higher number of public employees on the total of workers in the South than in the North that coupled with lower wages and lower taxes in the private sector (and possibly higher tax evasion as well), causes the flow of resources from North to South.

Figure 1: Public Employment per Resident

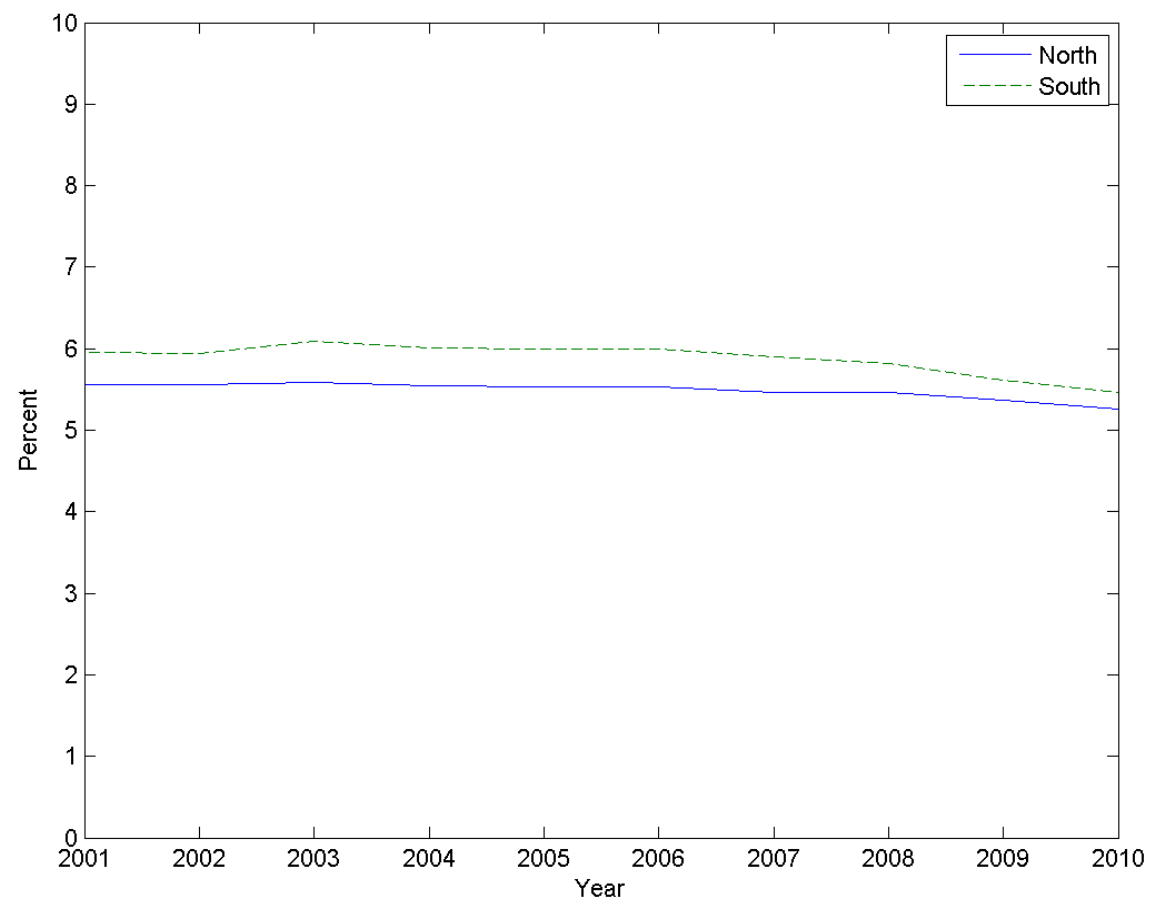

Data Source: Istat and from the Italian Ministry of Economy (Ragioneria Generale dello Stato).

Figure 1 adds to our picture some dynamics. It is very evident from the picture that 
the number of public employees has been dropping during the decade in Italy in general and more so in the South. This is true particularly staring from 2006/2007. The figure, together with the expectations that the fall of public employment will continue probably reinforced due to the effort to reduce the high public debt faced by the country, motivates the rest of the analysis in this paper. In fact, some important questions need to be answered about the effect of public employment on unemployment and private employment so that we can formulate accurate predictions of what happens when public employment is significantly reduced. The model I present in the following section is capable of interpreting the relationships between these variables and to generate quantifiable predictions, but before I present the model some other useful facts on employment, unemployment and wages need to be analyzed.

\subsection{Unemployment}

Figure 2 shows the evolution of unemployment rates in the North and the South of Italy between 1998 and 2012. Evidently unemployment has been about constant in both regions up to 2007 and then, because of the effect of the prolonged recession, has increased substantially across Italy. Interesting however, the increased seems to have been more dramatic in the South than in the North. The model I propose in the next section not only can explain the large unemployment gap between the regions of Italy in the steady state, which I assume is the situation up to 2007, but also can generate an asymmetric reaction to a common productivity shock, such that the south results more reactive than the North. In the model evaluation section I show this point. Meanwhile, the data that is important to extract from the figure is an average unemployment rate between 1998 and 2007 of $3.48 \%$ in the North compared to an average for the South of $19.05 \%$. The rates increase to $6.59 \%$ for the North and $27.66 \%$ for the South in 2012, that is, while for the North there is an increase of 3 percentage points, in the South the unemployment rate increases by more than $8 \%$.

Finally, it is also important to report the share of public employees on the total of the labor force as this has an impact on the probability that an unemployed person can find an occupation in the public sector, which will be the focus of the model below. Table 2 shows these data between 2001 and 2012. As we can see, the shares are not homogeneous across regions, being higher in the South than in the North. However, this is not, as shown above, 
Figure 2: Unemployment Rates in the North and South of Italy - 1998 to 2012

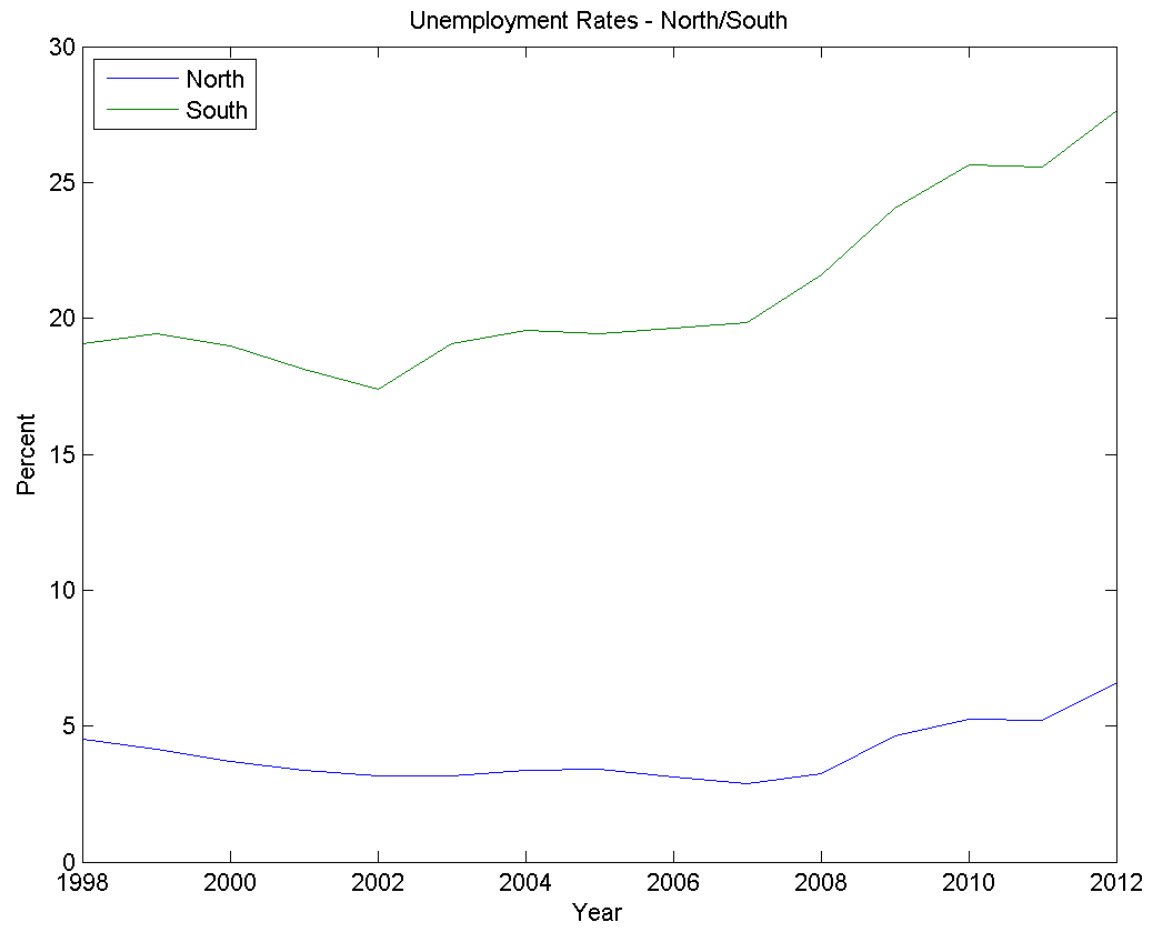

Data from ISTAT.

the result of an intentional policy that inflates the public sector in the South, rather is the effect of the lower participation of women in the South that leaves more public available to men 3

\section{$2.3 \quad$ Wages}

This sections presents evidence on hourly wages across areas of Italy. Alesina, Danninger and Rostagno (2001) already showed that public employees are homogeneously paid across regions of Italy while private employees are not. Alesina et alii report a wage gap between the North and the South in the private sector of about $14 \%$ while in then public sector is less than $1.5 \%$ and not statistically significant. They use data from SHIW from the year survey of 1995. With

\footnotetext{
${ }^{3}$ Why women participate less in the South than in the North is an open question and is beyond the scope of this paper. A model that could explain this puzzle would probably need to take into account the decision of different members within a household. It is possible that in the South, also because of lower living costs, wages earned by males have a stronger impact on the incentive to work of women and this, coupled with higher difficulties of finding jobs, generates lower participation. However, I leave this puzzle to further research.
} 
Table 2: Public Employment as Share of Labor Force

\begin{tabular}{lrrrr}
\hline \hline Year & \multicolumn{2}{c}{ North } & \multicolumn{2}{c}{ South } \\
& Men & Women & Men & Women \\
\hline 2001 & 9.94 & 16.90 & 13.87 & 21.26 \\
2002 & 9.88 & 16.95 & 13.96 & 21.33 \\
2003 & 10.32 & 16.82 & 14.41 & 21.73 \\
2004 & 9.97 & 17.02 & 14.39 & 21.98 \\
2005 & 9.89 & 17.02 & 14.21 & 22.76 \\
2006 & 9.59 & 17.20 & 14.19 & 23.08 \\
2007 & 9.26 & 17.11 & 14.07 & 23.22 \\
2008 & 9.14 & 16.97 & 13.91 & 22.57 \\
2009 & 9.11 & 16.70 & 13.71 & 22.46 \\
2010 & 8.87 & 16.51 & 13.36 & 21.93 \\
2011 & 8.72 & 16.19 & 13.38 & 21.52 \\
2012 & 8.50 & 15.69 & 12.72 & 19.98 \\
\hline Average (2001-2008) & 9.74 & 17.00 & 14.13 & 22.22 \\
\hline Average (2009-2012) & 8.80 & 16.27 & 13.29 & 21.47 \\
\hline
\end{tabular}

Elaboration on data from Istat and Ragioneria dello Stato.

a similar methodology and data from SHIW from 1998 to 2008, I obtain very similar results. In Figures 3 and 4 I show the kernel density estimated distribution of the log hourly wage rate residuals in the North and the South for private and public employment for the whole decade. The log hourly wage residuals are obtained by first regressing log hourly wages on a set of controls similar to those included in Alesina, with the exception of regional dummies ${ }_{4}^{4}$ The figures clearly show that, while in the private sector the distribution of residuals in the North is slightly on the right compared to that in the South, for the public sector those two distributions are hardly distinguishable.

Table 3 provides a formal test of the size and significance of the difference between Southern and Northern wages in the Private and Public sectors. As we can easily see from the table, in every year available in the survey the wage gap is not significant in the public sector, while it is in the private sector, ranging from about $5 \%$ in 2002 to $13.5 \%$ in 2006 . On Average, during the decade considered the gap is measure as $9.7 \%$.

\footnotetext{
${ }^{4}$ I include education dummies and occupational rank dummies, but I do not include controls for firm size and for marriage status. Also, I only include men and control for survey years.
} 
Figure 3: Density Kernel Estimation of Residual Wages - Private Sector

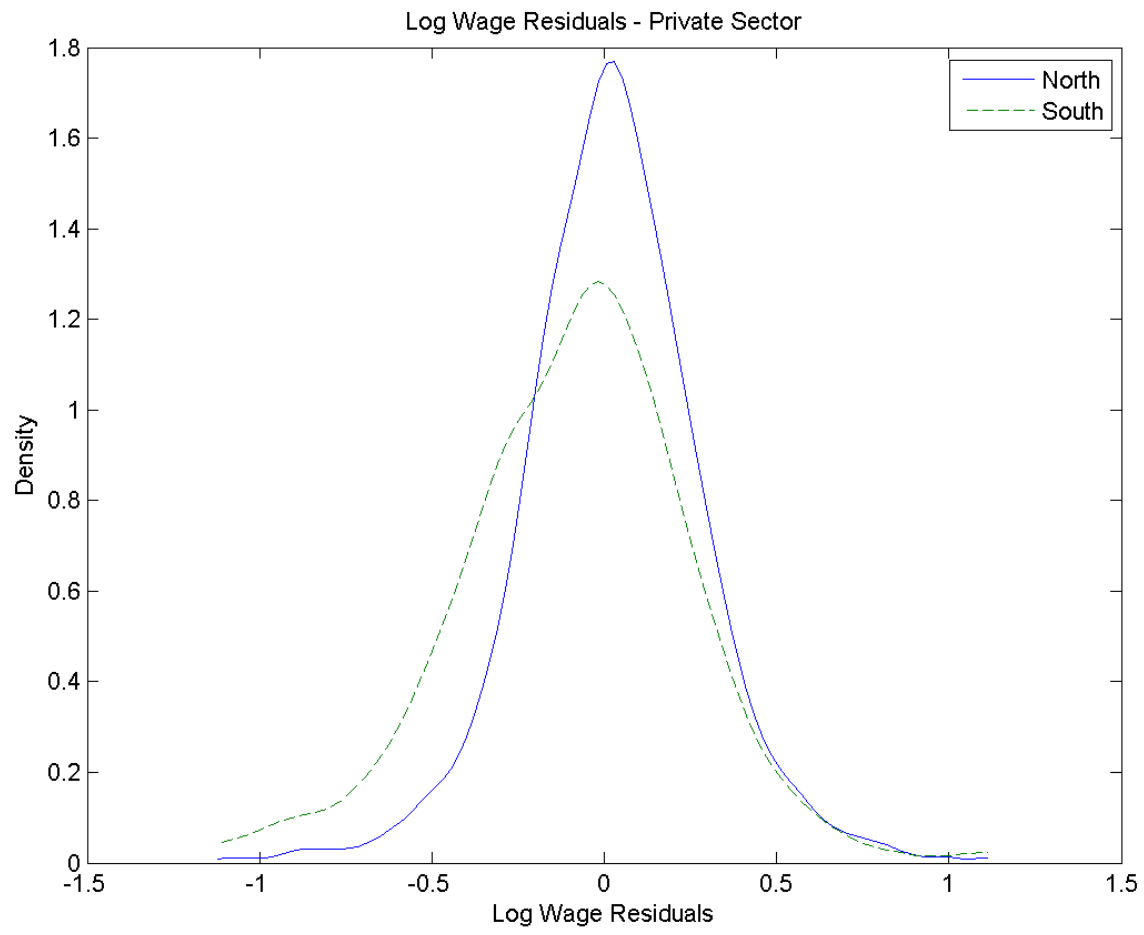

The residuals are calculated regressing log hourly wages on a set of personal characteristics and dummies for survey years. Details of the regressions in Appendix. Data: SHIW.

Table 3: Wage Regressions in the Private and Public Sector

\begin{tabular}{l|rrrrrrrr}
\hline Year & \multicolumn{4}{|c}{ Private Sector } & \multicolumn{5}{c}{ Public Sector } \\
\hline \hline Year & Sud & St. Err. & N. obs. & $R^{2}$ & Sud & St. Err. & N. obs. & $R^{2}$ \\
1998 & -0.1051 & 0.0148 & 2277 & 0.0218 & 0.0440 & 0.0213 & 960 & 0.0044 \\
2000 & -0.1626 & 0.0216 & 1378 & 0.0397 & -0.0813 & 0.0313 & 452 & 0.0147 \\
2002 & -0.1231 & 0.0228 & 1339 & 0.0214 & -0.0668 & 0.0334 & 437 & 0.0091 \\
2004 & -0.0806 & 0.0226 & 1413 & 0.0089 & -0.0412 & 0.0445 & 428 & 0.0020 \\
2006 & -0.1510 & 0.0203 & 1302 & 0.0406 & -0.0353 & 0.0424 & 358 & 0.0020 \\
2008 & -0.0912 & 0.0199 & 1202 & 0.0172 & -0.0419 & 0.0420 & 316 & 0.0032 \\
$1998-2008$ & -0.1171 & 0.0081 & 8911 & 0.0229 & -0.0207 & 0.0136 & 2951 & 0.0008 \\
\hline 2010 & -0.1109 & 0.0227 & 1054 & 0.0222 & 0.0582 & 0.0412 & 266 & 0.0075 \\
2012 & -0.0838 & 0.0251 & 1051 & 0.0105 & -0.0084 & 0.0431 & 246 & 0.0002 \\
$2010-2012$ & -0.0971 & 0.0169 & 2105 & 0.0155 & 0.0309 & 0.0298 & 512 & 0.0021 \\
\hline \hline
\end{tabular}

Author"s Computations on SHIW data. 
Figure 4: Density Kernel Estimation of Residual Wages - Public Sector

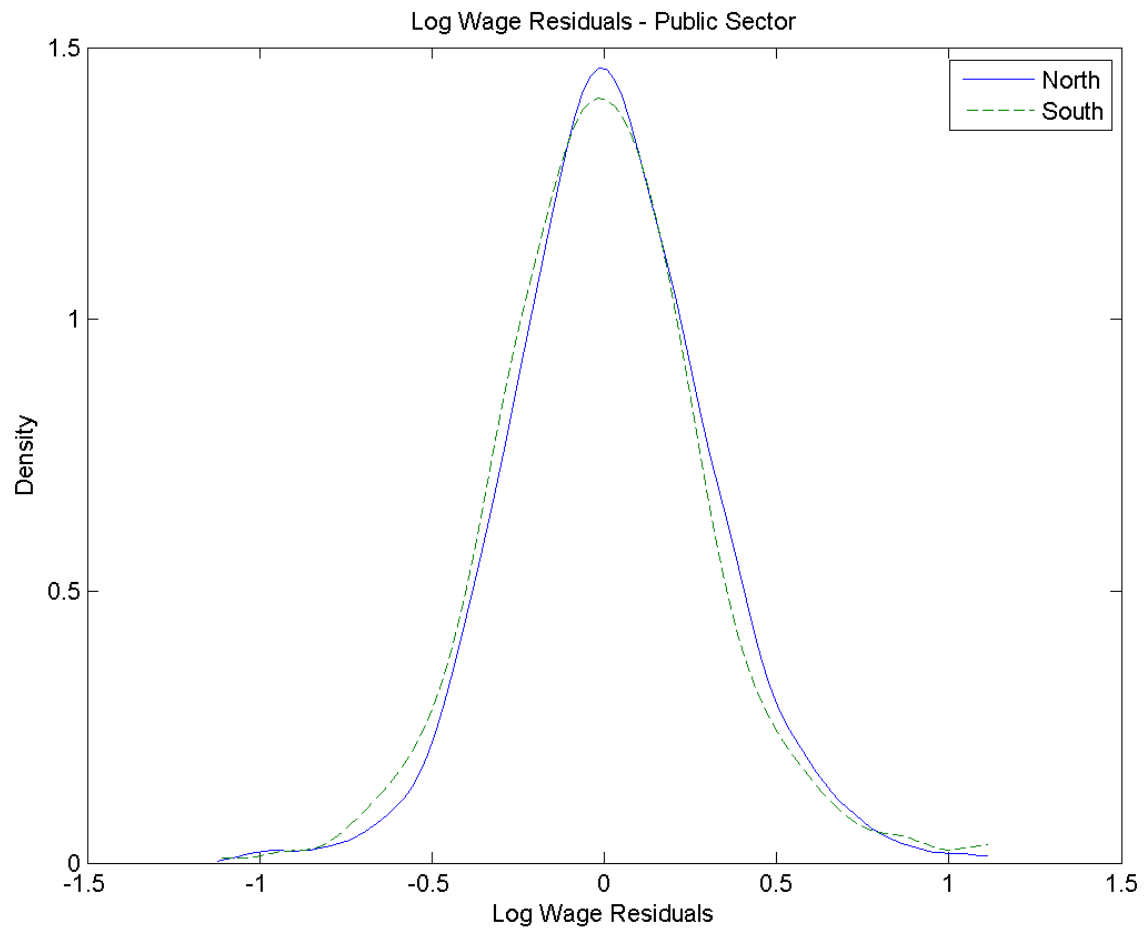

The residuals are calculated regressing log hourly wages on a set of personal characteristics and dummies for survey years. Details of the regressions in Appendix. Data: SHIW.

\section{The Model}

This section provides a full description of the model economy. The model is an extension of Mortensen and Pissarides (1999). There are two distinct geographical regions, characterized by different levels of total factor productivity, $p_{i}$. Each region has its own labor market in the sense that unemployed workers search exclusively in their region of residence. I follow Quadrini and Trigari (2007) and introduce a public sector that open vacancies in each region. The public sector, or the government, creates positions to provide public goods. Firms in the private sector create jobs in order to gain profits. Private firms open vacancies to fill job posts whenever the expected profit is positive. The government opens vacancies in order to satisfy an exogenous determined need of public goods. Differently from Quadrini and Trigari (2007), I assume that unemployed workers search in both the private and public sectors, therefore, at 
any point in time and in each labor market, unemployed workers meet with open vacancies, which can be from either sector. The rate at which unemployed workers and open vacancies meet is regulated by a meeting function $m_{i}\left(v_{i}, u_{i}\right)$, where $i$ stays for region, that depends on the number of unemployed workers and the total number of vacancies open, i.e. the sum of the vacancies open by private firms and the ones open by the government.

Upon meeting a private sector firm the worker and the employer observe the match specific productivity shock $\alpha$, and decide if the candidate is suitable for the job, i.e. if $\alpha$ is above the reservation value. If so, a match is created and the wage $w(\alpha)$, resulting from individual level Nash bargaining, is paid to the worker. After a match is created a worker can be hit by productivity shocks that arrive at a rate $\lambda$, which, exogenously, dissolves the match. Differently from the private sector, productivity in the public sector does not have an idiosyncratic component and is the same for all matches. The wage rate paid in the public sector is collectively bargained by unions with the government and is also the same for all public workers and the same across regions. This latest

Following Mortensen and Pissarides (1999) the meeting function is written as follows,

$$
m_{i}\left(v_{i}, u_{i}\right)=m\left(1, \frac{u_{i}}{v_{i}}\right) v_{i} \equiv q_{i}\left(\theta_{i}\right) v_{i} \text { where } \theta_{i}=\frac{v_{i}}{u_{i}},
$$

where $v=v^{p}+v^{g}$ is the sum of private and public (government) vacancies. Therefore, dropping the regional notation $i$

$$
q(\theta) v=q(\theta)\left(v^{p}+v^{g}\right)
$$

from which we can have,

$$
\frac{m(v, u)}{u}=q(\theta) \frac{v}{u}=q(\theta)\left(\theta^{p}+\theta^{g}\right)
$$

we can now give an interpretation of the functions found where $q(\theta)$ is the rate at which firms, either private or public, meet unemployed workers, while $q(\theta)\left(\theta^{p}+\theta^{g}\right)$ is the rate unemployed workers meet firms, or, loosely speaking, the probability at which they the find a position open. Moreover, while the rate at which firms meet workers is the same for public and private firms, the rate at which workers meet private firms or public firms $\left(q(\theta) \theta^{p}\right.$ and $\left.\left.q(\theta) \theta^{g}\right)\right)$ depends on the relative number of vacancies open in the two sectors. 
Finally, because of the idiosyncratic productivity shock, in the private sector, the rate at which vacancies are filled can be defined as follows

$$
q^{p}=q(\theta) \frac{\theta^{p}}{\theta} \int_{R}^{\bar{\alpha}} d F(\alpha)
$$

where $\bar{\alpha}$ is the upper limit of the shock distribution and $R$ is the reservation value. The rate at which unemployed workers find a job is,

$$
p^{p}=q(\theta) \theta^{p} \int_{R}^{\bar{\alpha}} d F(\alpha)
$$

In the public sector instead is,

$$
q^{p}=q(\theta) \frac{\theta^{g}}{\theta}
$$

and,

$$
p^{g}=q(\theta) \theta^{g}
$$

\subsection{Value of being Unemployed}

It is useful to start with the definition of the value of unemployment because it is from its definition that most of the relevant results of the model are generated. The unemployed worker receives an utility flow from her unemployment status indexed by $b 5^{5}$ However, unemployed workers are also actively engaged in searching for a job and the benefit of that search is given by the expected result. This is represented by the expected change in value sue to finding a private job, times the rate at which such jobs are found, plus the expected change in value due to obtaining a public job, times the rate at which those jobs arrive. That is, the flow value of unemployment is,

$$
r U=b+p^{p}\left(W_{p}^{e}-U\right)+p^{g}\left(W_{g}-U\right)
$$

\footnotetext{
${ }^{5}$ Since I calibrate the model to the Italian economy, I do not consider $b$ to be unemployment benefits paid by employment insurance schemes, as unemployment benefits are rare in Italy. Instead, I interpret it as utility flow from being unemployed, which also includes household production and within the household transfers of resources.
} 
where $W_{p}^{e}$ is the expected value of a private job and $W_{g}$ is the value of a public job, which if it arrives has a certain value because it does not depend on the ex ante unknown idiosyncratic productivity. It is already clear from the definition of unemployment what the effect of an increase in public job vacancies can be. If the government increases the vacancies of public jobs, the effect on $p^{g}$ is clearly positive, this increases the overall value of unemployment and, we should expect in this class of models, the reservation wage. This should generate a negative effect on the private employment, crowding out. However, there is another element to the model that can mitigate, or even nullify this effect, which is the government budget and the imposition of labor taxes to balance it. That is, more public jobs also increase public expenditure which requires higher taxes, and lower net wages, to be financed. Moreover, the other open question is, even if private employment decreases, will it decrease more or less than the increase of public employment? i.e. what would it be the overall effect on unemployment?

\subsection{Value of a match to a worker}

The value of a match in the private sector to a worker depends on the productivity specific to that match and is determined by the following asset equation,

$$
r W_{p}(\alpha)=w_{p}(\alpha)(1-t)+\lambda^{p} \int_{R}^{\bar{\alpha}}\left[U-W_{p}(\alpha)\right] d F(\alpha)-\lambda^{p} F(R)\left[W_{p}(\alpha)-U\right],
$$

where $w(\alpha)$ is the wage rate paid to the worker and $t$ is a proportional tax collected by the government in order to provide public job wages. the expected value of a private match to a worker is given by,

$$
r W_{p}^{e}=w_{p}^{e}(1-t)+\lambda^{p} F(R)\left(U-W_{p}^{e}\right)
$$

the value of a public match is instead given by,

$$
r W_{g}=w_{g}(1-t)+\lambda^{g}\left(U-W_{g}\right)
$$

Among other differences between private and public jobs is their expected duration which is determined by the different arrival rates of dissolving shocks $\lambda$. 


\subsection{Value of a match to an employer}

The value of a job to a private employer also depends on the productivity specific to that match. The productivity is the product of the shock $\alpha$ and the market specific productivity parameter $\pi$. Therefore the value of the job is

$$
r J_{p}(\alpha)=\pi \alpha-w(\alpha)+\lambda^{p} \int_{R}^{\bar{\alpha}}\left[V_{p}-J_{p}(\alpha)\right] d F(\alpha)-\lambda_{p} F(R)\left[J_{p}(\alpha)-V_{p}\right]
$$

taking the expectation of equation 9

$$
r J_{p}^{e}=\pi \alpha^{e}-w^{e}+\lambda_{p} F(R)\left(V_{p}-J_{p}^{e}\right)
$$

where the superscript $e$ indicates the expectation conditional on $\alpha$ being greater than $R$

$$
\alpha^{e}=E[\alpha \mid \alpha>R]
$$

I also assume that each public job generates an equally productive output within each region, therefore, the value of a job match for the government is given by,

$$
r G=\pi-w_{g}+\lambda_{g}\left(V_{g}-G\right)
$$

\subsection{Value of a posting a vacancy}

Finally, the value of posting a vacancy in the private sector is given by,

$$
r V_{p}=-c+q^{p}\left(J_{p}^{e}-V_{p}\right)
$$

while in the public sector is,

$$
r V_{g}=-c_{g}+q^{g}\left(G-V_{g}\right)
$$




\subsection{Wage Setting}

To keep things simple I assume that in the public sector the wage rate is determined exogenously by the government and is equal to the productivity of workers, plus the cost of opening a vacancy in the public sector ${ }^{6}$

$$
w_{g}=\pi+c_{g}
$$

For the private sector I follow the literature in assuming that the wage rate is determined by Nash bargaining, theretofore,

$$
w(\alpha)=\operatorname{argmax}\left(W_{p}(\alpha)-U\right)^{\beta}\left(J_{p}(\alpha)-V_{p}\right)^{1-\beta} .
$$

Which can be solved in terms of the flow value of unemployment as,

$$
[\beta+(1-\beta)(1-t)] w(\alpha)=\beta \pi \alpha+(1-\beta) r U
$$

Equation (16) is the textbook wage equation found for example in Pissarides (2000). What makes this equation different however, is the flow value of unemployment which includes the discounted value of finding a private sector job and the discounted value of finding a public sector job. Solving for the value of unemployment we can finally find an equation for $w(\alpha)$,

$$
w(\alpha)=\frac{1}{1-(1-\beta) t}\left[\beta \pi \alpha+\frac{r+\lambda^{g}}{p^{g}+r+\lambda^{g}}\left((1-\beta) b+\beta \theta_{p} c\right)+\frac{(1-\beta)(1-t) p^{g}}{p^{g}+r+\lambda^{g}} w_{g}\right]
$$

\subsection{Government}

The Government in this model decides how many public jobs are needed for supplying the public goods, i.e. sets $e_{g}$, the number of public jobs per person, and sets $t$ to pay for those public jobs. The budget constraint the government faces is given by

\footnotetext{
${ }^{6}$ This is equivalent to assuming that the wage is set by a monopolistic union that, as in Mortensen and Pissarides (1994), unilaterally determines the share of surplus that goes to workers as opposed to the share that goes to the Government. The government determines the size of public employment, that is the number of workers to hire. I also assume that the wage rate paid by the government is homogeneous across regions. The objective of the Unions is to maximize the value of the median worker, which in this case is the worker in the North, given that is the region with the higher concentration of labor force. That is, $w_{g}=\operatorname{argmax}_{\phi} W_{g}$ where, $W_{g}=U+\phi\left(W_{g}+G-V_{g}-U\right)$.. The solution to this particular problem is trivial since the unions set the share that goes to workers equal to one. The reason is that the separation rate is exogenous and not affected by the level of the wage.
} 


$$
w_{g}\left(\gamma_{n} e_{g n}+\gamma_{s} e_{g s}\right)+c *\left(v_{n}+v_{s}\right)=t\left(w_{g}\left(\gamma_{n} e_{g n}+\gamma_{s} e_{g s}\right)+\gamma_{n} w_{n}^{e} e_{p n}+\gamma_{s} w_{s}^{e} e_{p s}\right)
$$

$e_{g i}$ is the number of public employees over labor force in region $i, \gamma_{i}$ for $i=n, s$ is the share of the labor force in the Northern and Southern regions, and $e_{p i}$ is the employment rate in region $i$.

\section{Calibration}

Although the model is fairly simple and parsimonious, there are still fourteen parameters that need to be given numerical values and two functions to be given a specific form. My calibration strategy follows two basic criteria, on the one hand I rely on what has been done previously in the literature for the parameters and the functional forms for which I do not have direct evidence from Italian data; on the other hand, I use, as much as possible, the same data used to report the empirical facts above. Starting with the functional forms, I follow Pissarides and Petrongolo (2001) and I assign to the matching function a Cobb-Douglas form $m(u, v)=u^{\eta} v^{1-\eta}$ with $\eta=0.5$. To the idiosyncratic distribution of shocks I assign a log normal form in order to the distribution of the log-wage residuals presented in section 2. That is, $\alpha \sim \log N\left(0, \sigma^{2}\right)$.

For the bargaining power of workers and firms I choose to make a "neutral" assumption and set the value of the parameter $\beta$ equal to $0.5 .7 \mathrm{I}$ choose the interest rate to be 0.01 , a $4 \%$ annual interest rate.

The other parameters are chosen to match statistics directly or indirectly. The share of men in the labor force living in the North is $65 \%$, therefore I assign $\gamma=0.65$. The arrival rates of the shocks that break matches in the public and private sectors are set to match statistics of the number of jobs held by men lost over the total in those two sectors. For the public sector I take the statistics from the Ragioneria dello Stato on the number of public employees that cease to work for the public administration, over the total of the public employees, every year from 2001 to 2008. Averaging these number for the entire period $0.73 \%$ of public employees

\footnotetext{
${ }^{7}$ Since Italy has a labor market largely characterized by the strength of labor unions, this may seem a value hard to justify. However, the model does imply that unions have a strong effect on wages, both privately and publicly set, effect that comes indirectly through the wage setting process in the public sector.
} 
cease to work every three months, hence, since the break up rate for the public sector is exogenous, I directly set $\lambda^{g}=0.0073$. For the private sector I take the numbers given in Brutti (2011) for men, $3.31 \%$ for the North and $4.24 \%$ for the South as a quarterly average for the years 2004 to 20078 These statistics contribute to pin down the arrival rate of the shocks the change the match productivity, however, given that the actual destruction rate in the private sector is endogenous, they also contribute in pinning down other relevant parameters, such as the unemployment benefits, the cost of posting a vacancy and the variance of the shock distribution, which I do not match directly.

The shares of public jobs $e_{g i}$ are chosen to match the total number of men who hold public jobs over the total number of men in the labor force, therefore I set $e_{g n}=0.0974$ and $e_{g s}=0.14139$

The public sector wage setting rule in Quadrini and Trigari (2007) matches a premium that is paid to public workers in the US, and sets the wage rate in the public sector $3 \%$ higher than in the private sector. The data available for Italy say that, once personal characteristics such as education and experience are taken into account, public log-wages in the North are actually marginally lower than private sector log-wages by about $1.02 \%$. I normalize the public wage rate equal to one (i.e. I set the public sector productivity to be one and, consequently the wage rate as well) and use the public-private wage rate difference as a target to pin down the wage distributions. Additional targets for the distributions are the mean and variance differences of the log-wages distributions. I.e., I target the $11.71 \%$ wage gap between Southern and Northern wages, and I also target the $84.75 \%$ higher variance in the South compared to the North wage distribution 10 Finally, I target the unemployment rates in the North, the overall average for

\footnotetext{
${ }^{8}$ These numbers are not provided directly in Brutti (2011) as there are not detailed statistics for men in the North and the South. I derive these numbers first taking the probability of loosing a job for men in the whole country and then taking the estimated difference between men in the North and in the South, this being $0.91 \%$.

${ }^{9}$ Notice that these number are different from the ones presented above as are only for men and over the labor force, not the entire population. The significant difference between North and South is explained by the lower participation rate of women in the South that leaves more public jobs available to men. Of course, the large difference can also have an impact on explain unemployment gap, however, I conduct sensitivity re-calibrating the economy imposing the same number of public jobs available in the two regions and find that the difference in available public jobs has not impact in explaining the unemployment gap.

${ }^{10} \mathrm{I}$ do not calibrate the variance of the shock distribution using the actual variance of the residual wages from the data. The reason is that even though I do control for several important characteristics of individuals such as level of education and age, many other factors can imply a large heterogeneity across unemployed workers, for example the type of education or the quality of school attended, cannot be taken into account. The model assumes that unemployed agents are homogeneous and all the heterogeneity is post-meeting due
} 
men at $3.48 \%$ and leave that in the South free.

Because I have as many targets as parameters left to be determined, all the targets are matched exactly. In this case, an evaluation of the calibration can be obtained by looking at other statistics that can be obtained by the model simulation as compared to correspondent data statistic: 11

\subsection{Results and Model Evaluation}

Table 4 shows all the parameter values obtained through the calibration. In bold are the six parameters that are calibrated matching the six targets mentioned above. First can be noticed that the mean of the productivity distribution in the South is about $13 \%$ lower than in the North. This difference in values is primarily imposed by matching the $9.7 \%$ difference in the wage distribution between the two areas. The ex-ante productivity gap is larger than the wage gap, a clear effect of the geographically uniform public employment wage. The wage paid to public employees is relatively high in the South compared to the ex-ante average productivity in that region, this affects the bargaining process in the private sector increasing the southern workers outside option and, consequently, their wages.

A critical parameter to pin down in this type of models is the recruiting cost. The calibrated flow cost of recruiting is 0.1297 (column 5 in Table 4) about $12 \%$ of the average wage in the North and slightly higher in the South 12 This value implies that about $0.5 \%$ of the total wage bill is spent on recruiting, a value significantly lower to the one estimated by Michaillat (2012) for the US of $0.9 \%$. Finally, the flow value of being unemployed is calibrated to about $62 \%$ of the average wage rate in the North and $70 \%$ in the South. This value includes a large pool of resources that directly or indirectly benefit unemployed workers such as intra-family

to the idiosyncratic productivity shock attached to the match. For this reason we should expect the variance generated by the model lower than the variance of the residual wages, unless we are able to take into account all possible factors that explain ex-ante heterogeneity . However, if we assume that the unexplained ex-ante heterogeneity is distributed homogenously across regions in terms of first and second moments, we can look at the ratio between the variances in the North and the South.

${ }^{11}$ Alternatively, I could have chosen to over-identify the calibration and analyze the distance between the data and simulated moments. However, in order to have a proper measure of this distance I would also need a covariance matrix for weighting the data moments, which I don't have since some targets come from previous literature. Besides, I choose to calibrate based on the targets that are the most important given what the model aims at explaining, which is equivalent to giving these targets a infinite weight in an estimation.

${ }^{12}$ I also performed a calibration of a model where recruiting costs differ proportionally to the structural productivity between the South and the North, the results hold with approximately the same values. 
Table 4: Calibration - Parameter Values

\begin{tabular}{|c|c|}
\hline Parameter & North \\
\hline Productivity Distribution, Mean $\mu$ & $0.0000 \quad \mathbf{- 0 . 1 3 0 5}$ \\
\hline Shock arrival rate (priv) $\lambda^{p}$ & 0.0933 \\
\hline Shock arrival rate (gov) $\lambda^{g}$ & 0.0073 \\
\hline Variance shock distrib. $\sigma^{2}$ & 0.0698 \\
\hline Recruiting cost $c$ & 0.1297 \\
\hline Recruiting cost gov. $c_{g}$ & 0.0205 \\
\hline Unemployment Benefit $b$ & 0.6378 \\
\hline Interest rate $r$ & 0.0100 \\
\hline Matching elasticity $\eta$ & 0.5000 \\
\hline Bargaining Power $\beta$ & 0.5000 \\
\hline Public Empl. Share $e_{g}$ & $0.0974 \quad 0.1413$ \\
\hline Population Shares $\gamma$, and $1-\gamma$ & 0.6500 \\
\hline
\end{tabular}

Table 5: Calibrated Statistics

\begin{tabular}{lcc}
\hline Statistics & North & South \\
\hline \hline Unemployment Rate & 0.0348 & 0.0912 \\
Destruction Rate & 0.0331 & 0.0424 \\
Employment Rate & 0.8678 & 0.7675 \\
Average Wage & 1.0309 & 0.9170 \\
Reservation Wage & 0.9982 & 0.8921 \\
Public Sector Wage & 1.0205 & 1.0205 \\
Average Productivity & 1.0456 & 0.9312 \\
Reservation Productivity & 0.9800 & 0.8813 \\
Hiring Cost & 0.0019 & 0.0075 \\
Wage variance S/N & 1.8470 \\
Log-Wage. Diff. & -0.1171 \\
Tax Rate & \multicolumn{2}{c}{0.1221} \\
\hline
\end{tabular}

transfers, home production and, most importantly, a taste for leisure or that can be enjoyed while unemployed ${ }^{13}$ Finally, the rate of unemployment in the South is $9.12 \%$. While this result is about $7 \%$ lower than the actual unemployment reported by the above statistics, it shows that the model is capable of delivering a large unemployment rate gap between the regions due to a relatively small difference in average productivity, given the institutional setup of the economy.

\footnotetext{
${ }^{13}$ Only a very small fraction of unemployed workers can benefit from properly defined unemployed benefits in Italy. Most of the unemployed who never had a previous formal employment for a long enough period of time, do not qualify and cannot collect unemployment insurance. Those are the majority in the unemployed pool.
} 


\subsection{Sensitivity - The Importance of Public Employment}

In order to evaluate the importance of the public sector in determining the unemployment gap, I re-calibrate the model first with an equal share of public employment across regions and then without any public employment. In the first sensitivity calibration I set the rate of public employment equal to the national average in both regions, in the second exercise I set it equal to zero. All the calibration targets remain the same as before. In the second exercise the difference between public and private wage is dropped. Table 6 shows the parameter values of the new calibration, Table 7 the results ${ }^{14}$

Table 6: Calibration Sensitivity - Parameter Values

\begin{tabular}{|c|c|c|c|c|c|c|}
\hline & \multicolumn{2}{|c|}{ Benchmark } & \multicolumn{2}{|c|}{ Equal P.E } & \multicolumn{2}{|c|}{ No P.E. } \\
\hline Parameter & North & South & North & South & North & South \\
\hline Productivity Distribution, Mean $\mu$ & 0.0000 & -0.1305 & 0.0000 & -0.1287 & 0.0000 & -0.1231 \\
\hline Shock arrival rate (priv) $\lambda^{p}$ & \multicolumn{2}{|c|}{0.0933} & \multicolumn{2}{|c|}{0.0924} & \multicolumn{2}{|c|}{0.1062} \\
\hline Shock arrival rate (gov) $\lambda^{g}$ & \multicolumn{2}{|c|}{0.0073} & \multicolumn{2}{|c|}{0.0073} & \multicolumn{2}{|c|}{0.0073} \\
\hline Variance shock distrib. $\sigma^{2}$ & \multicolumn{2}{|c|}{0.0698} & \multicolumn{2}{|c|}{0.0717} & \multicolumn{2}{|c|}{0.0542} \\
\hline Recruiting cost $c$ & \multicolumn{2}{|c|}{0.1297} & \multicolumn{2}{|c|}{0.1292} & \multicolumn{2}{|c|}{0.1225} \\
\hline Recruiting cost gov. $c_{g}$ & \multicolumn{2}{|c|}{0.0205} & \multicolumn{2}{|c|}{0.0222} & \multicolumn{2}{|c|}{0.0000} \\
\hline Unemployment Benefit $b$ & \multicolumn{2}{|c|}{0.6378} & \multicolumn{2}{|c|}{0.6319} & \multicolumn{2}{|c|}{0.7905} \\
\hline Interest rate $r$ & \multicolumn{2}{|c|}{0.0100} & \multicolumn{2}{|c|}{0.0100} & \multicolumn{2}{|c|}{0.0100} \\
\hline Matching elasticity $\eta$ & \multicolumn{2}{|c|}{0.5000} & \multicolumn{2}{|c|}{0.5000} & \multicolumn{2}{|c|}{0.5000} \\
\hline Bargaining Power $\beta$ & \multicolumn{2}{|c|}{0.5000} & \multicolumn{2}{|c|}{0.5000} & \multicolumn{2}{|c|}{0.5000} \\
\hline Public Empl. Share $e_{g}$ & 0.0974 & 0.1413 & 0.1128 & 0.1128 & 0.0000 & 0.0000 \\
\hline Population Shares $\gamma$, and $1-\gamma$ & 0.3500 & 0.6500 & 0.3500 & 0.6500 & 0.3500 & 0.6500 \\
\hline
\end{tabular}

Table 6 reports the parameter values obtained in the two sensitivity calibrations (columns 3 to 6 ) and compares them with the values obtained in the benchmark calibration above, reported again in columns 1 and 2. The first exercise aims at evaluating the role of the different share of public employment over the labor force between the regions, i.e. how much, if at all, of the unemployment gap can be explained by public jobs be relatively more available to Southern men than Northerners. Table 7 shows that the parameters change little from the benchmark to the equal P.E. case. But is Table 7 that gives the answer. The unemployment in the South goes from $15.93 \%$ of the benchmark to $14.64 \%$ in case of equal share. While there is a small reduction, the gap remains quite large meaning that the differential share has

\footnotetext{
${ }^{14}$ I also re-calibrated the model with no taxes and with a fixed tax rate equal to the benchmark calibration. None of the alternative exercises bring significantly different results, therefore I do not report them for brevity.
} 
a small role in explaining the unemployment gap. Looking at columns 5 and 6 of Tables 6 and 7 is possible to assess the relevance of the institutional setting with public employment in generating the unemployment gap. Compared with the benchmark calibration the parameters that are significantly different are the cost of keeping a vacancy open $c$ and the flow value of being unemployed $b$. Both values are larger when the model is calibrated without public employment. Tower tax rate (6.83\% compared to $12.67 \%)$ tends to decrease the unemployment rate in the North, a target in the calibration, so that the other two parameters are calibrated to larger values to compensate. The interesting result, however is that the model now delivers an unemployment rate in the south equal to $12.06 \%$, which is about $4 \%$ lower than the benchmark calibration, together with an average and reservation wage rate in the public sector in the South about $1 \%$ lower than the benchmark value. Also in the North the average and reservation wages are lower, by about the same percentage, however the calibrated ex-ante productivity gap is now lower, and this explains the lower unemployment in this scenario compared to the benchmark. Without public employment with a homogenous wage rate paid to all public employees, the wage rate in the South is more aligned to the structural productivity as the outside option of unemployed workers is reduced by the absence of a relatively generous prospective public employer. Overall, the calibration of the model with public employment is capable of explaining at least a $4 \%$ more of the unemployment gap.

\section{Table 7: Calibration Sensitivity - Statistics}

\begin{tabular}{lcccccc}
\hline Statistics & North & South & North & South & North & South \\
\hline \hline Unemployment Rate & 0.0348 & 0.0912 & 0.0348 & 0.0829 & 0.0349 & 0.0707 \\
Destruction Rate & 0.0331 & 0.0424 & 0.0331 & 0.0424 & 0.0332 & 0.0424 \\
Employment Rate & 0.8678 & 0.7675 & 0.8524 & 0.8043 & 0.9651 & 0.9293 \\
Average Wage & 1.0309 & 0.9170 & 1.0327 & 0.9186 & 1.0188 & 0.9062 \\
Reservation Wage & 0.9982 & 0.8921 & 0.9993 & 0.8926 & 0.9912 & 0.8842 \\
Public Sector Wage & 1.0205 & 1.0205 & 1.0222 & 1.0222 & 0.0000 & 0.0000 \\
Average Productivity & 1.0456 & 0.9312 & 1.0479 & 0.9331 & 1.0290 & 0.9161 \\
Reservation Productivity & 0.9800 & 0.8813 & 0.9811 & 0.8811 & 0.9738 & 0.8721 \\
Hiring Cost & 0.0021 & 0.0090 & 0.0020 & 0.0074 & 0.0022 & 0.0066 \\
Wage variance S/N & 1.8470 & 1.8434 & 1.9238 \\
Log-Wage. Diff. & -0.1171 & -0.1171 & -0.1171 \\
Tax Rate & 0.1221 & 0.1219 & 0.0000 \\
\hline
\end{tabular}




\subsection{The Asymmetric Response to a Productivity Shock}

The model is calibrated to replicate a steady state economy and, as such, I use target values that averaged over a long period up to 2008, before Italy entered in a prolonged economic economic crisis. Starting from 2008 and especially in 2011 and 2012, unemployment in Italy increased substantially following the financial and sovereign debt crisis that affected all the Mediterranean Europe. However, noticeably the Southern regions are much more affected in terms of job loss than Northern regions. To see if the model is capable of generating such an asymmetric response to a possibly common productivity shock I simulate the model assuming a drop in productivity equal in both regions and such that I obtain an unemployment rate in the North about $2 \%$ points higher than the benchmark of $5.42 \%$, the average rate between 2009 and 2012. In the same period the unemployment rate in the South skyrocketed to $25.73 \%$, i.e. $6.7 \%$ higher than the previous period. Table 8 reports the results.

\begin{tabular}{l|cccccc}
\multicolumn{1}{c}{ Table 8: Simulation - Asymmetric response to an Aggregate Productivity Schock } \\
\hline \hline Statistics & \multicolumn{3}{|c}{ Benchmark } & Constant Taxes & Balanced Budget \\
\hline Statistics & North & South & North & South & North & South \\
\hline \hline Unemployment Rate & 0.0348 & 0.0912 & 0.0542 & 0.1460 & 0.0543 & 0.1464 \\
Destruction Rate & 0.0331 & 0.0424 & 0.0382 & 0.0475 & 0.0382 & 0.0475 \\
Employment Rate & 0.8678 & 0.7675 & 0.8578 & 0.7211 & 0.8577 & 0.7207 \\
Average Wage & 1.0309 & 0.9170 & 0.9688 & 0.8633 & 0.9688 & 0.8633 \\
Reservation Wage & 0.9982 & 0.8921 & 0.9399 & 0.8414 & 0.9400 & 0.8415 \\
Public Sector Wage & 1.0205 & 1.0205 & 1.0205 & 1.0205 & 1.0205 & 1.0205 \\
Average Productivity & 1.0456 & 0.9312 & 0.9831 & 0.8770 & 0.9831 & 0.8771 \\
Reservation Productivity & 0.9800 & 0.8813 & 0.9254 & 0.8333 & 0.9255 & 0.8333 \\
Hiring Cost & 0.0021 & 0.0090 & 0.0039 & 0.0186 & 0.0039 & 0.0187 \\
Wage variance S/N & 1.8470 & 1.4461 & 1.4471 \\
Log-Wage. Diff. & -0.1171 & -0.1153 & -0.1153 \\
Tax Rate & 0.1221 & 0.1221 & 0.1226 \\
\hline \hline
\end{tabular}

I simulate the case in which the tax rate does not react to balance the budged and the balanced budget equilibrium. The two do not differ substantially, mainly because I also take into account the change in the share of public employment in the two regions, which is negative and therefore compensate for the lower tax income due to lower employment. The table clearly shows that the model is capable of replicating the asymmetric growth in unemployment as the same productivity shock generates the targeted change of about $2 \%$ in the North and a 
correspondent change for the South of about $5.5 \%$, very close to the actual $6.6 \%$ change.

\section{$5 \quad$ Policy Experiments}

In the previous section when simulating the asymmetric response to a productivity shock I reduced the level of public employment in both regions according to the what we find in the data. In fact, most likely because of the efforts in reducing public debt, Italy is experiencing a slow, but continuous reduction of public employment mainly driven by not replacing or only partly replacing retiring public employees. In this section I conduct two policy experiments, one in which public employment is further reduced of an equal share in both regions, one in which I let the wage of public employees to be set regionally, according to the local productivity. A third experiment combines the two policies.

Table 9 resumes the results of the policy experiments. The first panel keeps the tax rate fixed across experiments and equal to the benchmark, the second panel presents the experiments under balanced budget. Starting from the first panel, lowering by $5 \%$ the share of public employment in both regions implies a reduction of unemployment in the South by about 1 percentage point, but an increase in the North, although very small. Columns 5 and 6 show the results of letting the wage of public employees adjust to the regional productivity. This means that while in the North the wage rate remains the same, in the South drops significantly by about $13 \%$. This policy has a significative effect on the Southern unemployment lowering it by about $4 \%$ points and no effect on the Northern unemployment. Finally, combining the policies does not bring better results than the heterogenous wage case in terms of unemployment. Indeed, once we lower public employment in the presence of heterogenous wages, the effect is of an increase in unemployment in both regions. Overall, what we can learn from the first panel is that keeping taxes fixed, the negative effect of public employment on total employment is present only when wages do not adjust to regional productivity, instead, when they do adjust higher public employment has the effect of lowering unemployment.

The second panel gives a slightly different picture. Because of the lower tax rate implied by a smaller public sector, now the economy is capable to generate more vacancies and employment in both regions, as a result in the first experiment with a $5 \%$ decrease in public employment unemployment decreases both in the North and the South. As in the previous 
Table 9: Simulation - Policy Experiments

\begin{tabular}{|c|c|c|c|c|c|c|c|c|}
\hline \multirow[b]{2}{*}{ Statistics } & \multicolumn{2}{|c|}{ Benchmark } & \multicolumn{2}{|c|}{ Lower P.E. } & \multicolumn{2}{|c|}{ "Heter. Wage } & \multicolumn{2}{|c|}{ "Combined } \\
\hline & North & South & North & South & North & South & North & South \\
\hline \multicolumn{9}{|l|}{ Constant Taxes } \\
\hline Unemployment Rate & 0.0348 & 0.0912 & 0.0364 & 0.0813 & 0.0348 & 0.0521 & 0.0364 & 0.0548 \\
\hline Destruction Rate & 0.0331 & 0.0424 & 0.0347 & 0.0426 & 0.0331 & 0.0356 & 0.0347 & 0.0375 \\
\hline Employment Rate & 0.8678 & 0.7675 & 0.9162 & 0.8274 & 0.8678 & 0.8066 & 0.9162 & 0.8539 \\
\hline Average Wage & 1.0309 & 0.9170 & 1.0310 & 0.9146 & 1.0309 & 0.9089 & 1.0310 & 0.9090 \\
\hline Reservation Wage & 0.9982 & 0.8921 & 0.9983 & 0.8890 & 0.9982 & 0.8816 & 0.9983 & 0.8817 \\
\hline Public Sector Wage & 1.0205 & 1.0205 & 1.0205 & 1.0205 & 1.0205 & 0.8982 & 1.0205 & 0.8982 \\
\hline Average Productivity & 1.0456 & 0.9312 & 1.0457 & 0.9286 & 1.0456 & 0.9223 & 1.0457 & 0.9224 \\
\hline Reservation Productivity & 0.9800 & 0.8813 & 0.9801 & 0.8774 & 0.9800 & 0.8677 & 0.9801 & 0.8678 \\
\hline Hiring Cost & 0.0021 & 0.0090 & 0.0020 & 0.0073 & 0.0021 & 0.0045 & 0.0020 & 0.0045 \\
\hline Wage variance $\mathrm{S} / \mathrm{N}$ & \multicolumn{2}{|c|}{1.8470} & \multicolumn{2}{|c|}{1.8760} & \multicolumn{2}{|c|}{1.9310} & \multicolumn{2}{|c|}{1.9303} \\
\hline Log-Wage. Diff. & \multicolumn{2}{|c|}{-0.1171} & \multicolumn{2}{|c|}{-0.1199} & \multicolumn{2}{|c|}{-0.1260} & \multicolumn{2}{|c|}{-0.1260} \\
\hline Tax Rate & \multicolumn{2}{|c|}{0.1221} & \multicolumn{2}{|c|}{0.1221} & \multicolumn{2}{|c|}{0.1221} & \multicolumn{2}{|c|}{0.1221} \\
\hline \multicolumn{9}{|l|}{ Balanced Budget } \\
\hline Unemployment Rate & 0.0348 & 0.0912 & 0.0311 & 0.0659 & 0.0341 & 0.0504 & 0.0308 & 0.0427 \\
\hline Destruction Rate & 0.0331 & 0.0424 & 0.0326 & 0.0399 & 0.0328 & 0.0352 & 0.0324 & 0.0342 \\
\hline Employment Rate & 0.8678 & 0.7675 & 0.9215 & 0.8428 & 0.8685 & 0.8083 & 0.9218 & 0.8660 \\
\hline Average Wage & 1.0309 & 0.9170 & 1.0289 & 0.9116 & 1.0306 & 0.9085 & 1.0287 & 0.9057 \\
\hline Reservation Wage & 0.9982 & 0.8921 & 0.9952 & 0.8851 & 0.9977 & 0.8810 & 0.9950 & 0.8773 \\
\hline Public Sector Wage & 1.0205 & 1.0205 & 1.0205 & 1.0205 & 1.0205 & 0.8982 & 1.0205 & 0.8982 \\
\hline Average Productivity & 1.0456 & 0.9312 & 1.0431 & 0.9252 & 1.0452 & 0.9218 & 1.0430 & 0.9187 \\
\hline Reservation Productivity & 0.9800 & 0.8813 & 0.9759 & 0.8723 & 0.9794 & 0.8669 & 0.9756 & 0.8618 \\
\hline Hiring Cost & 0.0021 & 0.0090 & 0.0017 & 0.0056 & 0.0020 & 0.0043 & 0.0017 & 0.0033 \\
\hline Wage variance $\mathrm{S} / \mathrm{N}$ & \multicolumn{2}{|c|}{1.8470} & \multicolumn{2}{|c|}{1.8606} & \multicolumn{2}{|c|}{1.9305} & \multicolumn{2}{|c|}{1.9092} \\
\hline Log-Wage. Diff. & \multicolumn{2}{|c|}{-0.1171} & \multicolumn{2}{|c|}{-0.1210} & \multicolumn{2}{|c|}{-0.1262} & \multicolumn{2}{|c|}{-0.1273} \\
\hline Tax Rate & \multicolumn{2}{|c|}{0.1221} & \multicolumn{2}{|c|}{0.0675} & \multicolumn{2}{|c|}{0.1151} & \multicolumn{2}{|c|}{0.0632} \\
\hline
\end{tabular}

experiment, reducing the wage rate of public employees in the South has an even stronger effect on unemployment. However, this time, because of the reinforcing effect of the tax rate, the effect is even stronger and is extended to the North as well. Finally, differently from before, combining the policy has now a stronger effect.

\section{Conclusions}

The focus of this paper is the macroeconomic effect that through the labor market public sector wages and employment has on private employment and unemployment. In particular I look 
at the geographical homogeneity of the wage rate paid by the government, as induced by the particular institutional set up od the government sector $[5$, and the effect that this has when regions are differently productive. I present a model in the spirit of Pissarides (2000), similar to the ones in Quadrini and Trigari (2007) and Gomes (2014). I calibrate the model to the Italian labor market and show a few results that are consistent with the previous literature, particularly with Gomes (2014). In particular I show that when public sector wages do not follow productivity, this has an amplifying effect on unemployment. In my case this adjustment is geographical rather than in the time domain (business cycle). Also, again similarly to Gomes, I show that public employment can have a stabilizing or de-stabilizing role on unemployment depending on the wage policy that the government pursues. With regard to the quantitative results from the calibration, I show that the model is capable to explain a large portion of the unemployment gap between the South and the North of Italy, i.e. about 6 of the 13 percentage points of difference. Moreover, it is also capable of explain the large asymmetric response to a productivity shock. Starting from 2008 and especially in 2011 and 2012, unemployment in Italy increased substantially following the financial and sovereign debt crisis. However, noticeably the Southern regions are much more affected than Northern regions. I simulate the model assuming a drop in productivity equal in both regions and such that the unemployment rate in the North is about $2 \%$ points higher than the benchmark of $5.42 \%$, which is the average rate between 2009 and 2012. In the same period the unemployment rate in the South skyrocketed to $25.73 \%$, i.e. $6.7 \%$ higher than the previous period. Indeed, the simulation results show a change in Southern unemployment of $5.5 \%$, close to the $6.7 \%$ in the statistics and significantly higher than the $2 \%$ in the North. I further simulate the model under different policy scenarios and show that reducing the size of public employment by a $5 \%$, reduces the unemployment in lower productivity regions by a $3 \%$ while allowing for regional wage setting in the public sector would almost eliminate the unemployment differential.

\footnotetext{
${ }^{15}$ set up that is more common in continental European countries such as France and Italy.
} 


\section{References}

A., Alesina, S. Danninger, and M. V. Rostagno, "Redistribution Through Public Employment: The Case of Italy," IMF Staff Papers, 2001, (48: 447-473).

Alesina, Alberto, Stephan Danninger, and Massimo Rostagno, "Redistribution Through Public Employment: The Case of Italy," IMF Staff Papers, 2001, 48 (3), 2.

Algan, Yann, Pierre Cahuc, and Andr Zylberberg, "Public employment and labour market performance," Economic Policy, 2002, 17 (34), 7-66.

Ardagna, Silvia, "Fiscal policy in unionized labor markets," Journal of Economic Dynamics and Control, May 2007, 31 (5), 1498-1534.

Brutti, Sergio Nocola, Flussi in Ingresso e Uscita dalla Disoccupazione: Analisi Dinamica delle Determinanti, Tesi di Laurea - Universita' di Padova, Padova, 2011.

Gomes, Pedro, "Optimal public sector wages," The Economic Journal, 2014, p. Forthcoming.

Lamo, Ana, Javier J. Prez, and A. Jsus Snchez-Fuentes, "Crowding-in or crowdingout?: employment in the public and the private sector in the OECD," Wages and employment: economics, structure and gender differences., 2013.

Malley, Jim and Thomas Moutos, "Does Government Employment Crowd-Out Private Employment? Evidence from Sweden," Scandinavian Journal of Economics, June 1996, $98(2), 289-302$.

_ and __ , "Capital Accumulation and Unemployment: A Tale of Two Continents.," Scandinavian Journal of Economics, March 2001, 103 (1), 79-99.

Michaillat, Pascal, "Do Matching Frictions Explain Unemployment? Not in Bad Times," American Economic Review, June 2012, 102 (4), 1721-50.

Mortensen, Dale T. and Christopher Pissarides, "New Developments in Models of Search in the Labour Market," CEPR, 1999, (DP.2053). 
Pappa, Evi, "The Effects Of Fiscal Shocks On Employment And The Real Wage," International Economic Review, 02 2009, 50 (1), 217-244.

Pissarides, Christopher A., Equilibrium Unemployment Theory, 2nd Edition, Vol. 1 of MIT Press Books, The MIT Press, 2000.

and Barbara Petrongolo, "Looking into the Black Box: A Survey of the Matching Function," Journal of Economic Literature, June 2001, 39 (2), 390-431.

Quadrini, Vincenzo and Antonella Trigari, "Public Employment and the Business Cycle," Scandinavian Journal of Economics, 2007, 109 (4), 723-742. 